Dhaka Univ. J. Biol. Sci. 28(2): 227-231, 2019 (July)

- Short communication

\title{
EFFECTS OF 2, 3, 5-TRIIODOBENZOIC ACID ON THE ANATOMICAL CHANGES OF CHICKPEA VAR. BARI CHOLA-7
}

\author{
SAIFUl IsLAM* AND PARVEen RASHID \\ Plant Physiology Laboratory, Department of Botany, University of Dhaka, \\ Dhaka-1000, Bangladesh \\ Key words: Chickpea, TIBA, Foliar application, Anatomical changes
}

The use of synthetic plant growth regulators to regulate plant growth has become an important tool in many agricultural and horticultural practices. Among the synthetic plant growth regulators, TIBA, a polar auxin transport inhibitor is widely used. At low concentration, it is capable of checking the excessive vegetative growth and lodging tendency, reducing the abscission of flowers and immature pods, and modifying the crop canopy to improve the productivity of crops $^{(1)}$.

Physiological modifications as well as improved yield and yield attributes caused by TIBA have been reported in various economically important crop plants viz. soybean(2), groundnut(3), tomato ${ }^{(4)}$ and chickpea(5). While the effects of TIBA on the external appearance of plants are well known, limited information is available as to its effects upon the internal structure(6).

Chickpea (Cicer arietinum L.) is one of the major pulse crops in Bangladesh and is the third most important food legume grown in the world after beans and peas. It is one of the important sources of protein in the dietary uptake of the people of Bangladesh. It is ranked fifth in area but second in consumption priority ${ }^{(7)}$. The present investigation was undertaken to study the effects of TIBA on the anatomical structure of root and shoot in chickpea.

A field experiment was carried out at the research field of the Department of Botany, University of Dhaka during Rabi (December-March) season of 2017-2018. Seeds of BARI Chola-7 were collected from BARI (Bangladesh Agricultural Research Institute), Joydebpur, Gazipur. The experimental soil was analyzed and low levels of potassium and very low levels of nitrogen and phosphorus were recorded ${ }^{(8)}$. Cowdung, urea, TSP and MP were applied at basal amount during final land preparation. The experiment was laid out in randomized block design with four replications. The unit plot size was $2 \mathrm{~m} \times$ $1.1 \mathrm{~m}$. Seeds were sown on 29th November, 2017 in rows having a gap of $40 \mathrm{~cm}$. Plants in rows were maintained $15 \mathrm{~cm}$ apart by thinning seedlings at 15 days after sowing. Intercultural operations were done as and when necessary. Five foliar treatments, viz. water spray (control), 10, 20,50 and 100 ppm TIBA, respectively, were tested against

*Author for correspondence: <saiful.botany@du.ac.bd>. 
chickpea var. BARI Chola-7. The foliar spray was done at 45 days after sowing by using separate sprayers. Three weeks after treatment, control plants and $20 \mathrm{ppm}$ TIBA treated plants which showed positive physiological effects were collected and preserved in FAA (formalin-acetic acid-alcohol) solution for anatomical study. Free hand cross sections of both root and shoot were taken and stained in safranin. Root sections were taken $0.5 \mathrm{~cm}$ below the root collar and stem sections were taken $4 \mathrm{~cm}$ above the soil line. Photomicrograph of the stained specimens were taken using Trinocular Res. microscope with digital camera system (Axiocam ERc 5s, Zeiss, Germany).

Effects on anatomy of stem: 20 ppm TIBA treated plants showed an increase (Table 1, Fig. 1A, B) in diameter of the stem compared to the control though pith diameter showed a marginal decrease. Similar results were also reported by Berova and Zlatev ${ }^{(9)}$ in tomato and by Tsegaw et al.(10) in potato. Due to $20 \mathrm{ppm}$ TIBA, significant changes occurred in the number and size of xylem vessels. In TIBA treated plants, number of vessels in stem increased considerably though their size or average diameter $(0.50 \pm 0.30)$ of the cavity decreased compared to the control plants. In addition, the xylem vessels are more uniformly distributed throughout the diameter of the stem of TIBA treated plants than those of control. Research workers reported different results in different plant species with respect to TIBA and other auxin transport inhibitor induced stem anatomical modifications. Kroll and Moore ${ }^{(6)}$ reported decrease in the number of xylem vessels in soybean stem following TIBA application at $70 \mathrm{~g} / \mathrm{h}$. However, Robnett and Morey ${ }^{(11)}$ observed an increased number of xylem elements in 2,4-D and 2,4-T treated plant stems. Mattsson et al.(12) noticed increased number of vascular tissues in the NPA (1-Nnaphthylphtalamic acid)-treated plants. Krause ${ }^{(13)}$ reported production of small vessels in soybean following TIBA application.

Table 1. Effect of TIBA on stem and root characteristics. Mean value of four observations \pm standard deviation.

\begin{tabular}{lcc}
\hline Diameter & Control plants & Treated plants \\
\hline Stem $(\mathrm{mm})$ & $2.08 \pm 0.20$ & $2.22 \pm 0.30$ \\
Stem pith $(\mu \mathrm{m})$ & $5.80 \pm 0.70$ & $5.60 \pm 0.60$ \\
Stem vessel $(\mu \mathrm{m})$ & $0.60 \pm 0.20$ & $0.50 \pm 0.30$ \\
Root $(\mathrm{mm})$ & $3.50 \pm 0.30$ & $4.13 \pm 0.30$ \\
Root pith $(\mu \mathrm{m})$ & $3.40 \pm 0.40$ & $4.20 \pm 0.20$ \\
Root vessel $(\mu \mathrm{m})$ & $0.80 \pm 0.30$ & $0.70 \pm 0.30$ \\
\hline
\end{tabular}

Effects on anatomy of root: In plants receiving $20 \mathrm{ppm}$ TIBA, diameter of both root and pith increased (Table 1, Fig. 2A, B) noticeably compared to the control. Moreover, diameter of root was greater than that of stem in both control and TIBA treated plants. 

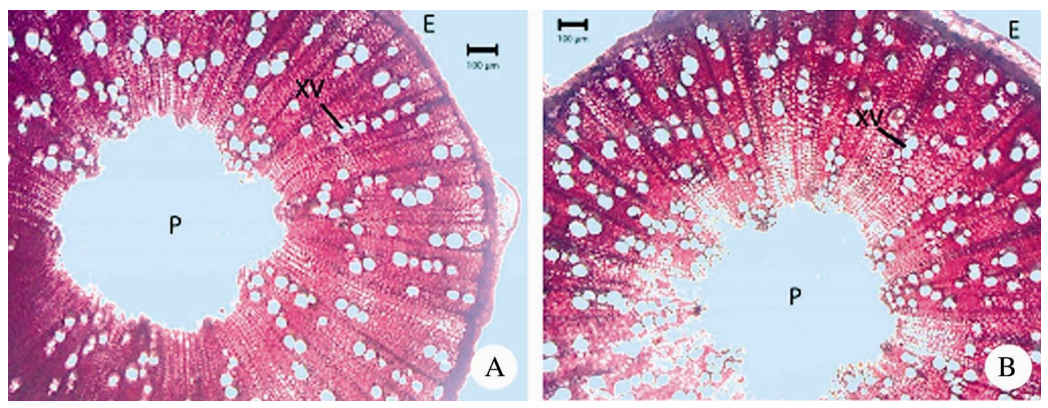

Fig. 1. A, B. Transverse section (50× magnification) of the stem of the control (A) and $20 \mathrm{ppm}$ TIBA treated plants $(\mathrm{B})$ of Cicer arietinum $\mathrm{L}$. var. BARI Chola-7. $\mathrm{P}=$ pith, $\mathrm{XV}=$ xylem vessel, $\mathrm{E}=$ epidermis.

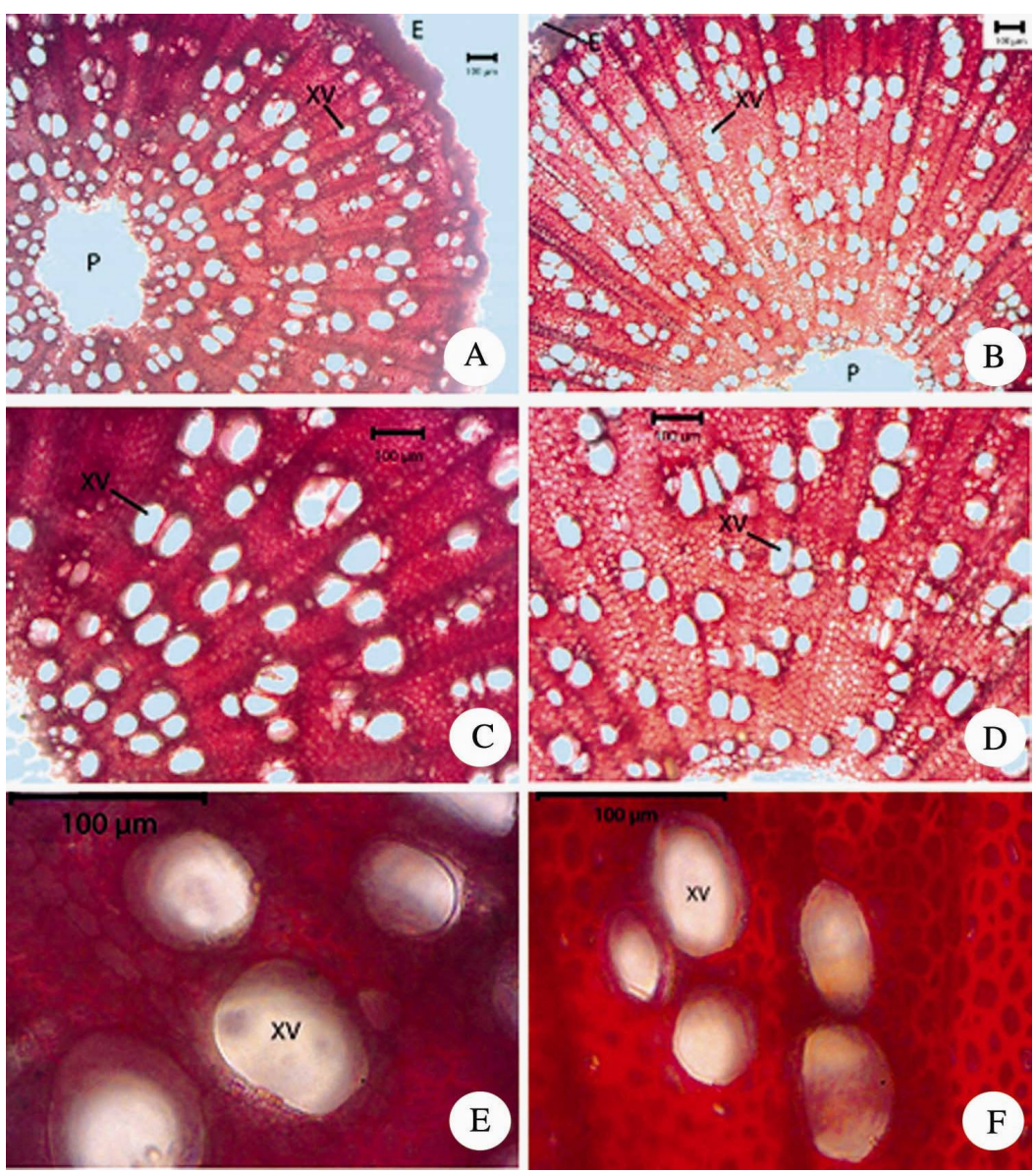

Fig. 2. A-F. Transverse section of the root of the control (A,C,E) and $20 \mathrm{ppm}$ TIBA treated plants (B, D, F) of Cicer arietinum L. var. BARI Chola-7. $\mathrm{P}=$ pith, $\mathrm{XV}=$ xylem vessel, $\mathrm{E}=$ epidermis. $\mathrm{A}, \mathrm{B}$ (50× magnification); C, D (100× magnification); E, F (400× magnification). 
Increased root diameter following growth retarding chemical application was also reported in other plants, viz. soybean ${ }^{(14)}$ and potato(10). Burrows et al.(15) found reduced stem diameter but roots with increased diameter in chrysanthemum due to similar growth retarding chemical PBZ. The most significant changes that occurred due to 20 ppm TIBA treatment was in the number and sizes of the xylem vessels. The xylem vessel diameter in TIBA-treated roots decreased compared to the control (Fig. 2C-F). But, 20 ppm TIBA induced the formation of more secondary xylem vessels in root and they were evenly distributed within the radii because of continuous production. This result is also in consistent with the findings of Tsegaw et al.(10) in potato.

Galston ${ }^{(16)}$ suggested that TIBA antagonizes and may completely negate the effect of IAA. It may do this by competing for a carrier or by accelerating the destruction of IAA. Kamien and Skoog ${ }^{(17)}$ and Hay ${ }^{(18)}$ concluded that low concentrations of TIBA primarily affected the polarity of auxin, rather than the destruction of it. Aberg(19) indicated that at high concentration, TIBA antagonized the effect of externally applied auxin and apparently also the natural auxin and caused a growth inhibition. However, at low amounts TIBA had weak auxin effects which might be due to a synergistic action upon residual amounts of the native auxin. Therefore, depending on the plant species and the concentration applied, TIBA may either stimulate or inhibit plant growth, thereby affecting morphological and anatomical modifications. The study confirms that TIBA treatment can induce similar anatomical modifications in a wide range of crops. The effect of TIBA on the induction of anatomical changes may be mediated by changing the hormonal balance of the plant.

\section{References}

1. Adam AMM and N Jahan 2014. Growth and yield of BARI Mung-5 (Vigna radiata L. Wilczek) following TIBA application. Dhaka Univ. J. Biol. Sci. 23(2):179-185.

2. Deotale RD, DS Katekhaye, NV Store, JS Raut and VJ Golliwar 1995. Effect of TIBA and $\beta$ nine on morphological characters of soybean. J. Soils Crops 4(2): 172-176.

3. Kler DS and GS Dhillon 1993. Effect of cycocel and TIBA spray on the pod yield of groundnut. Environ. Ecol. 11(2): 475.

4. Mondal MMA and RK Dutta 2002. Effect of TIBA (2,3,5-triiodobenzoic acid) on growth and yield of tomato. J. Agril. Res. 40(3-4): 273-279.

5. Islam S and N Jahan 2016. Growth analysis of chickpea var. BARI Chola-7 following application of TIBA (2, 3, 5- triiodobenzoic acid). J. Bangladesh Acad. Sci. 40(2): 199-205.

6. Kroll TK and LD Moore 1981. Effect of 2,3,5-triiodobenzoic acid on the susceptibility of soybeans toMacrophominaphaseolina. Plant Disease 65(6): 483-485.

7. BBS. Statistical Year Book of Bangladesh 2014. Bangladesh Bureau of Statistics, Planning Division, Ministry of Planning, Government of the People's Republic of Bangladesh.

8. FRG. 2012. Fertilizer Recommendation Guide. Bangladesh Agricultural Research Council (BARC), Farmgate, Dhaka 1215. pp. 274. 
9. Berova M and Z Zlatev 2000. Physiological response and yield of paclobutrazol treated tomato plants (Lycopersicon esculentum Mill). Plant Growth Regulat. 30(2): 117-123.

10. Tsegaw T, S Hammes and J Robbertse 2005. Paclobutrazol-induced leaf, stem and root anatomical modifications in potato. Hort. Science 45(5): 1343-1346.

11. Robnett WE and PR Morey 1973. Wood formation in Prosopis: Effect of 2,4-D, 2,4,5-T and TIBA. Amer. J. Bot. 60: 745-754.

12. Mattsson J, ZR Sung and T Berleth 1999. Responses of plant vascular systems to auxin transport inhibition. Development 126: 2979-2991.

13. Krause BF 1971. Structural and histological studies of the cambium and shoot meristems of soybean treated with 2,3,5-triiodobenzoic acid. Amer. J. Bot. 58(2): 148-159.

14. Barnes AM, RH Walser and TD Davis 1989. Anatomy of Zea mays and Glycine max seedling treated with triazole plant growth regulators. Biol. Plant. 31: 370-375.

15. Burrows GE, TS Boag and WP Stewart 1992. Changes in leaf, stem, and root anatomy of Chrysanthemum cv. Lillian Hoek following paclobutrazol application. Journal of Plant Growth Regulator 11: 189-194.

16. Galston AW 1947. The effect of 2,3,5-triiodobenzoic acid on the growth and flowering of soybeans. Amer. J. Bot. 31: 356-360.

17. Kamien EN and F Skoog 1956. Studies on polarity and auxin transport in plants. I. Modification of polarity and auxin transport by triiodobenzoic acid. Physiol. Plant. 9: 60-73.

18. Hay JR 1956. The effect of 2,4-dichlorophenoxiacetic acid and 2,3,5-triiodobenzoic acid on the transport of indoleacetic acid. Plant Physiol. 31: 118-120.

19. Aberg B 1953. On the interaction of 2,3,5-triiodobenzoic acid and maleic hydrazide with auxins. Physiol. Plant. 6: 277-291. 